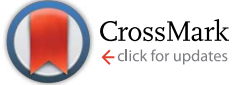

Cite this: J. Mater. Chem. A, 2016, 4, 16394

Received 30th May 2016

DOI: $10.1039 / c 6 t a 04499 a$

www.rsc.org/MaterialsA
Accepted 15th September 2016

\section{Inexpensive electrochemical synthesis of nickel iron sulphides on nickel foam: super active and ultra-durable electrocatalysts for alkaline electrolyte membrane water electrolysis $\dagger$}

\begin{abstract}
Pandian Ganesan, Arumugam Sivanantham and Sangaraju Shanmugam*
Efficient and durable electrocatalysts for water splitting (both the oxygen evolution reaction (OER) and hydrogen evolution reaction (HER)) are required for the replacement of expensive noble metal-based catalysts used in water electrolysis devices. Herein, we describe the inexpensive synthesis of electrochemically deposited nickel iron sulphides on nickel foam (NiFeS/NF) and their use as highly efficient bi-functional water splitting catalysts that can meet the current energy demands. The NiFeS/ $\mathrm{NF}$ electrocatalysts exhibited low overpotentials of approximately $231 \mathrm{mV}$ for the OER and $180 \mathrm{mV}$ for the HER in $1 \mathrm{M} \mathrm{KOH}$. Moreover, the NiFeS/NF electrocatalysts exhibited a turnover frequency of one order of magnitude higher than those of state-of-the-art noble metal catalysts $\left(\mathrm{RuO}_{2}\right.$ and $\left.\mathrm{Pt} / \mathrm{C}\right)$ for the OER and HER. In addition to this excellent activity, the bi-functional catalyst also exhibited an outstanding OER and HER electrode stability for over $200 \mathrm{~h}$ with minimal loss in activity. Further, it can be directly used in the practical application of alkaline electrolyte membrane water electrolysis. The high performance, prolonged electrode stability, and facile synthesis as an adherent coating on nickel foam suggest that NiFeS/NF electrocatalysts might be suitable for use as alternative commercially viable catalysts.
\end{abstract}

\section{Introduction}

The production of clean hydrogen through water splitting is a sustainable way of generating renewable energy. ${ }^{1-5}$ Hydrogen production through polymer electrolyte membrane (PEM) water splitting does not produce $\mathrm{CO}_{2}$ emissions if the electricity is derived from a renewable source (e.g., wind, solar), but it must be sufficiently efficient and inexpensive to compete with hydrogen production from steam reforming of fossil fuel sources., ${ }^{\mathbf{4} 6-8}$ The efficiency of a water electrolyzer system is limited, in part, by the kinetic overpotential losses associated with driving the oxygen evolution reaction (OER) at the anode and the hydrogen evolution reaction (HER) at the cathode under both acidic and basic environments. ${ }^{9-12}$ Solar water splitting also provides the ability to integrate a photovoltaic device (for energy conversion) and an electrolyzer (for energy storage) within a single device, thereby further lowering the cost of hydrogen production. ${ }^{3}$

The Department of Energy has stated that the levelized hydrogen plant production cost using green energy, in terms of

Department of Energy Systems and Engineering, Daegu Gyeongbuk Institute of Science \& Technology (DGIST), 50-1 Sang-Ri, Hyeongpung-Myeon, Dalseong-gun, Daegu, 42988, Republic of Korea.E-mail: sangarajus@dgist.ac.kr

$\dagger$ Electronic supplementary information (ESI) available. See DOI: 10.1039/c6ta04499a gallon gas per equivalent (gge) of $\mathrm{H}_{2}$, must decrease from $\$ 3$ in 2015 to $\$ 2$ in 2020 . Of the total cost of constructing a water electrolyzer, $41 \%$ of the expense in MEA assembly arises from making a better stack of the PEM water electrolyzer. ${ }^{13,14}$ Hence, a cost-effective way of preparing a catalyst that is supported directly on the MEA without an additional current collector would decrease the contact resistance and improve the performance. Nickel current collectors are used widely in PEM water electrolyzers because of their high activity and stability in alkaline media., ${ }^{7,8,15}$ Although many OER and HER catalysts have been reported, nickel and iron alloys are among the most highly active in alkaline environments and also exhibit good stability with high current densities (up to 100-500 $\mathrm{mA} \mathrm{cm}{ }^{-2}$ ).,10,15 The role of iron in a NiFe alloy is to prevent the nickel from electrode corrosion during prolonged electrochemical operation in alkaline environments. ${ }^{8,16}$ Several nickel and iron-based materials (e.g., NiFe/ $\mathrm{NF}, \mathrm{Fe}-\mathrm{Ni}_{3} \mathrm{~S}_{2} / \mathrm{NF}, \mathrm{Ni}_{3} \mathrm{~S}_{2} / \mathrm{NF}, \mathrm{NiFeO}_{2}$, nickel iron oxyhydroxide and cobalt phosphides) have been reported recently for use as water splitting catalysts. ${ }^{\mathbf{9}, 10,15,17-27}$ Although nickel sulphides and selenides on nickel foams (NFs) have been prepared as OER and HER catalysts, they require high overpotentials to afford high current densities and exhibit very poor long-term durability. ${ }^{15,20,25-28}$ To the best of our knowledge, nickel iron sulphides grown directly on NF for both the OER and HER with long-term durability in alkaline media have not been reported previously. 
(b) (a)

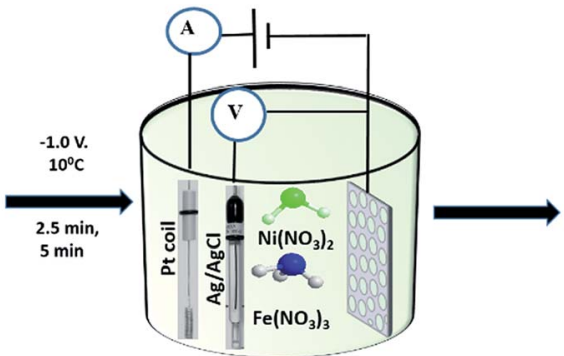

Nickel foam (NF)

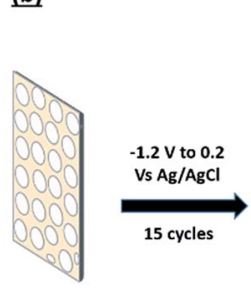

$\mathrm{NiFe} / \mathrm{NF}$
Chronoamperometry

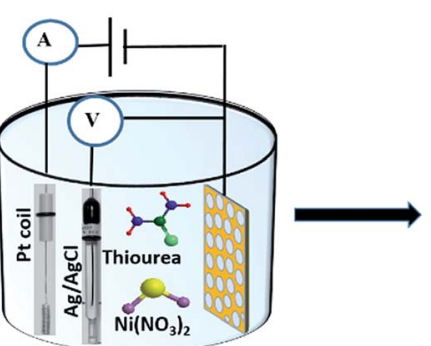

Cyclic Voltammetry deposition

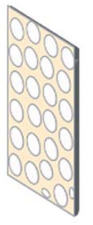

NiFe/NF

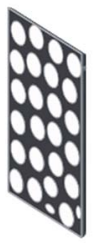

NiFes/NF

Fig. 1 Schematic illustration of electrochemical deposition of nickel iron sulphides on nickel foam: (a) nickel iron deposition on nickel foam and (b) sulphide deposition on nickel iron foam.

Herein, we describe the inexpensive synthesis of electrochemically deposited nickel iron sulphides (NiFeS/NF) supported on NF (Fig. 1). Our NiFeS/NF electrocatalyst is highly stable in alkaline environments for a long time, functions with low overpotentials of 231 and $180 \mathrm{mV}$ for the OER and HER, respectively and affords very high current densities for longterm OER and HER activity. Its performance is much better than that of the metal sulphides (e.g., $\mathrm{Fe}_{11.8 \%} \mathrm{Ni}_{3} \mathrm{~S}_{2} / \mathrm{NF}$, NiS/Ni foam, $\mathrm{NiFe} \mathrm{LDH} / \mathrm{NF}$ ) reported previously; in addition, the synthesized $\mathrm{NiFeS/NF}$ is practically applicable to alkaline membrane full water splitting devices. The NiFeS/NF catalyst also exhibits performance close to that of state-of-the-art noble catalysts (e.g., $\mathrm{Pt} / \mathrm{C}, \mathrm{RuO}_{2}$ ).

\section{Experimental section}

\section{Materials and methods}

Nickel foam (NF, thickness: $1.6 \mathrm{~mm}$ ) and stainless steel (304 grade, thickness, $0.25 \mathrm{~mm}$ ) were purchased from MTI Korea Ltd. Nickel chloride, iron chloride nonahydrate, and thiourea were purchased from Alfa Aesar. The nickel iron sulphides were characterized using X-ray diffraction (XRD) for phase confirmation. XRD measurements were carried out using the X-ray diffractometer (Rigaku, MiniFlex 600) with $\mathrm{CuK} \alpha$ radiation (1.5418 $\AA$ ). The morphology of the samples was examined by using a field-emission scanning electron microscope (FE-SEM, Hitachi, S-4800II, 3.0 kV). Before the SEM observation, the samples were sputtered with osmium coating. The transmission electron microscopy (TEM) measurements were made using a Hitachi HF-3300, $300 \mathrm{kV}$ instrument. The nickel iron sulphides were dispersed in isopropanol by sonication in an ultrasonic agitator for $30 \mathrm{~min}$ to peel off the deposited nickel

iron sulphide film from the Ni foam; a drop of the solution was dispersed on a copper grid, dried under an UV lamp and subjected to TEM measurements. X-ray photoelectron spectroscopy (XPS) measurements were performed using a Thermo-scientific, ESCALAB 250Xi model in an ultrahigh vacuum of $10^{-9}$ mbar.

\section{Synthesis of NiFe/NF}

First, the NF was sonicated in $3 \mathrm{M} \mathrm{HCl}$ solution for $10 \mathrm{~min}$ to remove any $\mathrm{NiO}_{x}$ layer present on the surface, subsequently washed thoroughly with water and ethanol, and then dried in air. The electrodeposition was carried out using NF as the working electrode, a platinum wire as the auxiliary electrode and $\mathrm{Ag} / \mathrm{AgCl}(3 \mathrm{M} \mathrm{KCl})$ as the reference electrode. The analyte solution consists of $3 \mathrm{mM} \mathrm{Ni}\left(\mathrm{NO}_{3}\right)_{2} \cdot 6 \mathrm{H}_{2} \mathrm{O}$ and $3 \mathrm{mM}$ $\mathrm{Fe}\left(\mathrm{NO}_{3}\right)_{3} \cdot 9 \mathrm{H}_{2} \mathrm{O}$. Chronoamperometry was then carried out at $-1.0 \mathrm{~V}$ at $10{ }^{\circ} \mathrm{C}$. The deposition was varied for 2.5 and $5 \mathrm{~min}$, and the deposited samples were labelled as NiFe-1 and NiFe-2, respectively (Fig. 1a). The optimized deposition time of NiFe on $\mathrm{NF}$ was found to be $2.5 \mathrm{~min}$. After deposition, the nickel foams were carefully withdrawn from the electrolyte, rinsed with water and ethanol, then sonicated in ethanol and left to dry in air. ${ }^{29}$ The iron deposited on the nickel foam was heat treated to $500{ }^{\circ} \mathrm{C}$ in an argon atmosphere for $5 \mathrm{~h}$ (Fig. S1a $\dagger$ ).

\section{Synthesis of NiFeS/NF}

The deposition of nickel and sulphide on the NiFe/NF, nickel foam, and for a control sample, the deposition also made on stainless steel electrodes were performed through cyclic voltammetry (CV) using the analyte of $50 \mathrm{mM} \mathrm{NiCl} 2 \cdot 6 \mathrm{H}_{2} \mathrm{O}$ and $1 \mathrm{M}$ thiourea (TU). The three-electrode setup featured $\mathrm{NF}$ or the $\mathrm{NiFe} / \mathrm{NF}$ substrate as the working electrode, saturated $\mathrm{Ag} / \mathrm{AgCl}$ as the reference electrode, and a Pt wire as the counter electrode and was monitored using a computer-controlled potentiostat (Bio-Logic) electrochemical analyzer. CV was performed by sweeping between $-1.2 \mathrm{~V}$ and $+0.2 \mathrm{~V}$ at a scan rate of $5 \mathrm{mV} \mathrm{s}^{-1}$ for 15 sweep cycles (Fig. 1b). After electrodeposition, the asdeposited electrodes were rinsed with deionized water and dried for $12 \mathrm{~h}$ in a vacuum oven at $60{ }^{\circ} \mathrm{C} .{ }^{30}$ During the cyclic voltammetric deposition of sulphide on the NiFe-1/NF electrode, the Ni(Thiourea) ${ }_{2}{ }^{2+}$ intermediate is formed during the oxidative potential sweep (eqn (1)) and $\mathrm{Ni}$ (Thiourea) ${ }_{2}{ }^{2+}$ reduces and forms nickel iron sulphide $\left(\mathrm{Ni}_{2} \mathrm{FeS}_{4}\right)$ on the NiFe-1/NF electrode surface (eqn (2)) as previously reported for cobalt sulphide $^{31}$ (Fig. S1b $\dagger$ ). Hence, the coating thickness was due to the total coating of the nickel iron sulphide (Fig. S3a $\dagger$ ).

$$
\begin{aligned}
& \mathrm{Ni}^{2+}+2 \text { thiourea } \rightarrow \mathrm{Ni}(\text { Thiourea })_{2}{ }^{2+} \\
& \mathrm{Ni}(\text { Thiourea })_{2}{ }^{2+}+\mathrm{NiFe} \rightarrow \mathrm{Ni}_{2} \mathrm{FeS}_{4}
\end{aligned}
$$

The products from the deposition of sulphide on NiFe-1/NF, NiFe-2/NF, and NF are named herein NiFeS-1/NF, NiFeS-2/NF, and $\mathrm{Ni}_{3} \mathrm{~S}_{2} / \mathrm{NF}$, respectively. The thickness of the film coating of NiFeS-1 on NF was measured to be $2.71 \mu \mathrm{m}$ (Fig. 1b). The NiFeS$1 / \mathrm{NF}$ heat treated to $500{ }^{\circ} \mathrm{C}$ in an Ar atmosphere exhibited a clear phase of $\mathrm{Ni}_{2} \mathrm{FeS}_{4}$ (Fig. $\mathrm{S} 1 \mathrm{~b} \dagger$ ) and also the cyclic 
voltammetric deposition of nickel and sulphide on the stainless steel foil was achieved (Fig. S1c $\dagger$ ).

\section{Electrochemical measurements}

The electrochemical activities of all nickel foams were evaluated using linear sweep voltammetry (LSV) in an Ar-saturated atmosphere for the hydrogen evolution reaction (HER) and without saturation for the oxygen evolution reaction (OER) at a scan rate of $10 \mathrm{mV} \mathrm{s}^{-1}$ using a computer controlled potentiostat (Bio-Logic) with a typical three-electrode system. The working electrode was immersed in a glass cell containing $1 \mathrm{M}$ $\mathrm{KOH}$ aqueous electrolyte. A platinum coil and saturated calomel electrode (SCE) served as counter and reference electrodes, respectively. In order to compare the OER and HER activities, the commercial $\mathrm{Pt} / \mathrm{C}(40 \%)$ and $\mathrm{RuO}_{2}$ catalysts were used. The catalyst ink was prepared using five milligrams of the catalyst dispersed in a mixture consisting of $160 \mu \mathrm{L}$ of isopropanol, $30 \mu \mathrm{L}$ of DI water and $10 \mu \mathrm{L}$ of Nafion solution and the contents were dispersed by ultrasonication for approximately $30 \mathrm{~min}$ to obtain a homogeneous suspension. The catalyst ink $(1.5 \mu \mathrm{L})$ was drop cast onto the surface of a glassy carbon disk (working electrode, $0.07 \mathrm{~cm}^{2}$ ) and dried at room temperature. All potentials reported in this work were converted from the SCE to the RHE scale using $((\mathrm{RHE})=E(\mathrm{SCE})+1.030 \mathrm{~V})$ in $1 \mathrm{M} \mathrm{KOH}$. The LSV of all nickel foam electrodes was characterized by electrochemical impedance spectroscopy (EIS) in the frequency range of 200 to $100 \mathrm{mHz}$ at $0 \mathrm{~V}$ to calculate $i R$ correction, transfer resistance, and double layer capacitance. The $i R$ correction was calculated based on the solution resistance and is about $2.25 \mathrm{ohm}$, obtained from the EIS. The sulphide coating thickness and weight of NiFeS-1/NF were calculated using a Mitutoya screw gauge (5477300) and an OHAUS microbalance (PAG214C model), respectively.

\section{Preparation of MEA}

NiFeS-1/NF is used as the anode and cathode prepared by the electrochemical deposition with $1.5 \mathrm{~cm}^{2}$ nickel foams (Fig. S2a $\& \mathrm{~b} \dagger$ ). The assembly was made with stainless steel electrodes (Fig. S2c \& $d \dagger$ ) and the Fump Sep alkaline membrane (Tokuyama, A201) which was pre-treated with $1 \mathrm{M} \mathrm{KOH}$ for $24 \mathrm{~h}$ and then washed with DI water and then used for MEA assembly. The fuel cell equipment from the Heliocentric device (Germany) was used as the PEM water electrolyzer.

\section{Results and discussion}

\section{Structure and morphology analysis}

Fig. 2 displays XRD patterns for the NF, NiFe-1/NF and NiFeS-1/ $\mathrm{NF}$ electrocatalysts. In the low-intensity region, NiFe-1/NF appeared to be amorphous with a peak shift of only $0.26^{\circ}$ for the nickel substrate peak. The XRD patterns were analysed before and after heat treatment of NiFe-1/NF. Unlike the as-deposited, the heat treated NiFe-1/NF exhibits the NiFe phase (PDF no. 00012-0736) with a nickel to iron ratio of $\sim 1: 1$ (Fig. S1a †). This behaviour explains the effect of iron on nickel in NiFe-1/NF. In contrast, the XRD pattern of NiFeS-1/NF featured (220), (533),

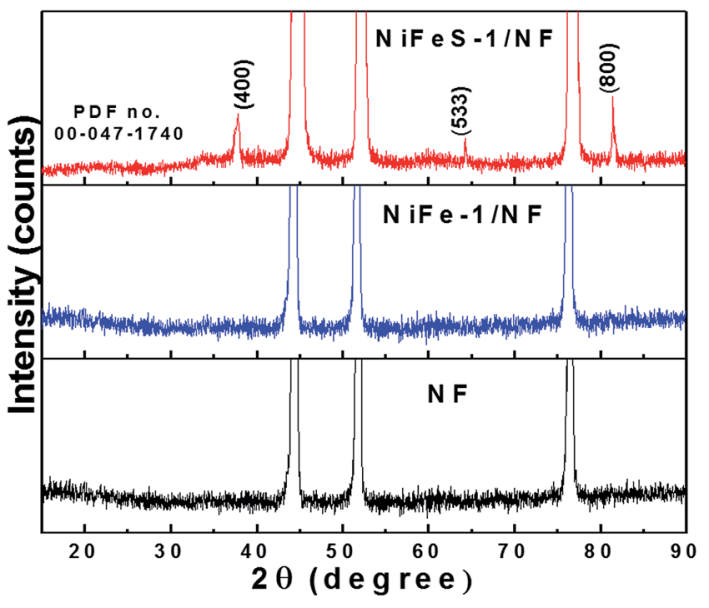

Fig. 2 XRD patterns of NiFeS-1/NF, NiFe-1/NF and NF electrodes.

(400), and (800) diffraction patterns indicative of the formation of a $\mathrm{Ni}_{2} \mathrm{FeS}_{4}$ phase (PDF no. 00-047-1747). These peaks were, however, less intense than those of the NF substrate, due to the deposition only on the nickel surface (Fig. 1b). The remaining peaks were less prominent than those of the nickel substrate, due to the minimum diffraction of X-rays and amorphous nature of the iron deposited in the first deposition step (Fig. 1a)..$^{29}$ Further, the NiFeS-1/NF heat treated to $500{ }^{\circ} \mathrm{C}$ in an Ar atmosphere shows the clear phase of $\mathrm{Ni}_{2} \mathrm{FeS}_{4}$ compared to the as-synthesised NiFeS-1/NF which evidences that the iron was not present in the bottom layer or separate coating, instead the iron exists as a nickel iron sulphide composite (Fig. S1b†). In addition, we have carried out a control experiment to understand the influence of the substrate, and cyclic voltammetric deposition of nickel and sulphide on the stainless steel (SS304) foil was also performed. The XRD analysis (Fig. S1c†) of this product exhibits a NiS phase (PDF no. 01-075-0612). This observation clearly explains the involvement of iron in the sulphide deposition exclusively. And also the cyclic voltammetric deposition on NiFe-1/NF without thiourea in the analyte was also performed and the XRD phase analysis reveals (Fig. S3b†) the peaks of NiO (PDF no. 03-0652865). This clearly confirms that in the presence of thiourea, the metal oxide formation is least probable. In addition, we indexed the XRD pattern of the electrodeposited nickel sulphide to $\mathrm{Ni}_{3} \mathrm{~S}_{2}$ (PDF no. 01-074-1336) in the absence of the iron impurity, ${ }^{30,32,33}$ as displayed in Fig. $\mathrm{S} 4 ; \dagger$ it was entirely different from the $\mathrm{Ni}_{2} \mathrm{FeS}_{4}$ phase observed for the NiFeS-1/NF sample. In Fig. 3a, the SEM image reveals the film thickness of NiFeS-1 to be about $2.71 \mu \mathrm{m}$ on NF; Fig. $3 \mathrm{~b}$ reveals the nano-honeycomb structure of NiFeS-1 on NF. The NiFeS-2/NF sample possessed a morphology similar to that of NiFeS-1/NF (Fig. S5a and $b \dagger$ ). The elemental SEM-EDS analysis was carried out on the upper, middle and bottom region of the NiFeS-1 layer on NF as shown in Fig. S6a $\uparrow$ and the corresponding ratio of nickel, iron, and sulphur is listed in Table S1. $\dagger$ The nickel, iron and sulphur in the upper coating (Fig. S6b $\dagger$ ) is about 96.06, 2.29 and $1.65 \%$, respectively, the middle coating contains (Fig. S6c $\dagger$ ) about 96.24, 2.70 and 1.06\% of nickel, iron, and sulphur, respectively and the bottom coating 

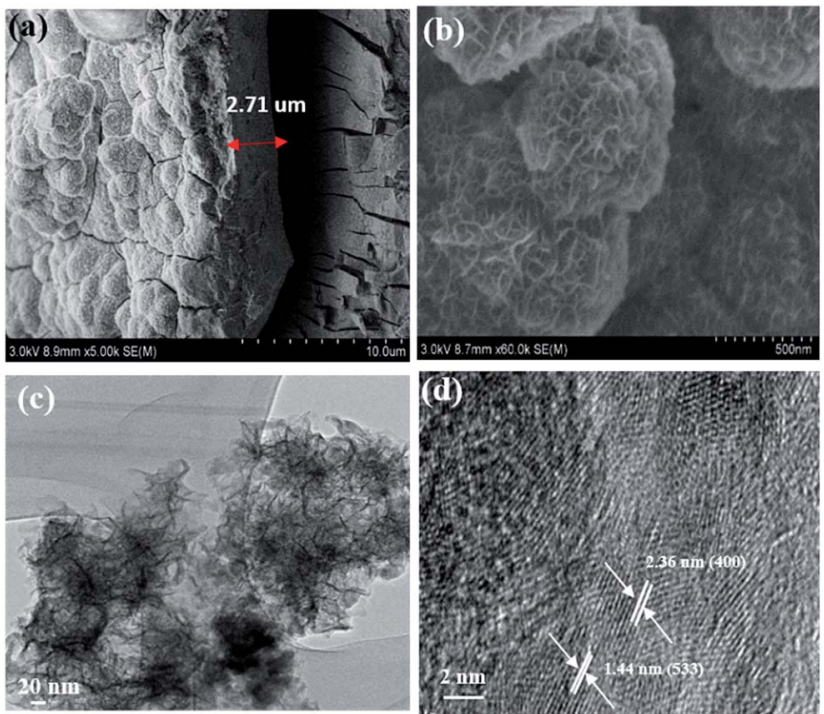

Fig. 3 SEM images: (a) low magnification of NiFeS-1 coating on NF, (b) high magnification distribution. (c) TEM and (d) HR-TEM images of the NiFeS-1 nanosheet detached from the surface of the NF.

(Fig. S6d $\dagger$ ) contains about 96.60, 2.44 and $1.10 \%$ of nickel, iron, and sulphur, respectively. From Table S1, $\dagger$ it was obvious that throughout the coating of NiFeS-1/NF, the ratio of nickel, iron, and sulphur content was almost equal. This observation reveals the fact that iron exists uniformly throughout the catalyst layer. The TEM image in Fig. 3c confirmed the honeycomb structure of NiFeS-1/NF with vein-like projections on the surface of the catalyst. The high-resolution TEM image in Fig. 3d reveals fringe widths of approximately 2.36 and $1.44 \mathrm{~nm}$ that correspond to the (400) and (533) planes, respectively, of the $\mathrm{Ni}_{2} \mathrm{FeS}_{4}$ phase in NiFeS-1/NF, confirming the presence of nickel, iron, and sulfur atoms as a composite. The TEM elemental mapping (Fig. S7†) confirmed the presence of nickel, sulfur, and iron atoms in the NiFeS-1/NF honeycomb with surface-adsorbed oxygen (Fig. S7a-f $\dagger$ ).

\section{XPS analysis}

We recorded XPS spectra to examine the chemical environment of NiFeS-1/NF and NiFe-1/NF. The XPS discussion of NiFe-1/NF (details in ESI section $3 \dagger$ ) exhibits metallic nickel and iron along with adsorbed hydroxides (Fig. S8 $\dagger$ ). The XPS spectra of fresh NiFeS-1/NF (Fig. 4a) featured a Ni ${ }^{3+} 2 \mathrm{p}_{3 / 2}$ peak at $858.5 \mathrm{eV}$, suggesting that nickel atoms may have been bonded to both iron and sulfur atoms. ${ }^{32}$ Moreover, the signal near $861.8 \mathrm{eV}$ indicated the presence of an oxidation state of $\mathrm{Ni}^{2+}$ relevant to nickel sulphide, ${ }^{1,17,33}$ but there was a shift of $0.3 \mathrm{eV}$ from the characteristic Ni-S oxidation states, possibly because of the incorporation of iron atoms. The main signal at $856.3 \mathrm{eV}$, with its satellite peak at $864.3 \mathrm{eV}$, revealed the presence of surfaceadsorbed nickel oxide. ${ }^{7,19,34}$ Taken together, these features are consistent with the presence of a NiFeS film in the NF. Signals for metallic nickel in the range of $852.0-856.0 \mathrm{eV}$ were absent for NiFeS-1/NF, ${ }^{33}$ suggesting that all of the nickel atoms on the NiFe-1 surface were completely converted into NiFeS without

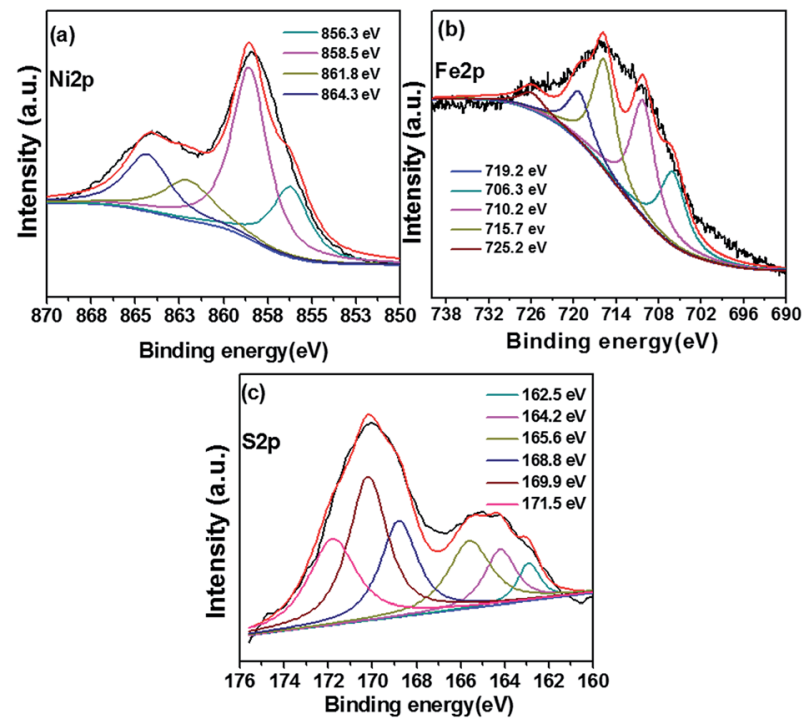

Fig. 4 XPS spectra of (a) nickel (Ni 2p), (b) iron (Fe 2p) and (c) sulphur (S $2 p)$ of the fresh NiFeS-1/NF electrode.

any impurities. The Fe $2 \mathrm{p}_{3 / 2}$ spectrum (Fig. $4 \mathrm{~b}$ ) of fresh NiFeS-1/ $\mathrm{NF}$ featured a signal at $725.2 \mathrm{eV}$ characteristic of the oxidation state of the nickel iron sulphide composite. ${ }^{19}$ Signals at 706.7 and $719.2 \mathrm{eV}$ revealed that some of the iron atoms in this structure were in the $\mathrm{Fe}(0)$ oxidation state; ${ }^{\mathbf{8} 20}$ signals at 710.3 and $715.4 \mathrm{eV}$ revealed that some of the iron atoms also existed as $\mathrm{FeO}$ in the +2 oxidation state. ${ }^{\mathbf{1 0 , 3 5}}$ Fig. 4c displays the $\mathrm{S} 2 \mathrm{p}$ spectra, the characteristic signal appeared at $169.9 \mathrm{eV}$ (ref. 19) for the oxidation state of nickel iron sulphide and also the characteristic oxidation state of a metal disulphide peak at $162.5 \mathrm{eV}$, suggesting that existence of nickel, iron and sulfur atoms may have been bonded together as $\mathrm{Ni}_{2} \mathrm{FeS}_{4} \cdot{ }^{35,36}$ The signal at $164.2 \mathrm{eV}$ confirmed the presence of surface oxygen adsorbed Ni-S on the nickel surface; the presence of surface oxygen was further evidenced by the sulfoxide peak at $\mathbf{1 6 5 . 6}$ $\mathrm{eV} \cdot{ }^{35-37}$ Although sulfate and sulfite peaks were present at 168.8 and $171.5 \mathrm{eV}$, respectively, the intensity of the sulfur oxidation peak at $169.9 \mathrm{eV}$, relevant to the nickel iron sulphide composite, was much higher than those of the others, consistent with the composite having the $\mathrm{Ni}_{2} \mathrm{FeS}_{4}$ phase, as determined from the XRD pattern. ${ }^{19,35,36}$

\section{Electrochemical activity}

To examine the OER behavior of NiFeS-1/NF, NiFe-1/NF, $\mathrm{Ni}_{3} \mathrm{~S}_{2} /$ $\mathrm{NF}$, and $\mathrm{RuO}_{2}$, LSV was performed between 1.0 and $1.9 \mathrm{~V} v s$. RHE in $1 \mathrm{M} \mathrm{KOH}$. To achieve a current density of $100 \mathrm{~mA} \mathrm{~cm}^{-2}$, the NiFeS-1/NF, NiFe-1/NF, and $\mathrm{Ni}_{3} \mathrm{~S}_{2} / \mathrm{NF}$ catalysts required overpotentials of approximately 231, 371, and $491 \mathrm{mV}$, respectively (Fig. 5a). Similarly, we recorded OER linear sweep voltammograms for NiFeS-2/NF and NiFe-2/NF, our examined catalysts; the activity of $\mathrm{NiFeS}-1 / \mathrm{NF}$ was greater than that of NiFeS-2/NF because it required the lowest overpotential (ca. $231 \mathrm{mV}$ ) to achieve a current density of $100 \mathrm{~mA} \mathrm{~cm}^{-2}$ (Fig. S9a $\dagger$ ). When comparing the $\mathrm{Ni}_{3} \mathrm{~S}_{2} / \mathrm{NF}$, NiFe-1, and NiFe-2 alloys, $\mathrm{NiFeS}-1 / \mathrm{NF}$ displayed the greatest OER performance. Notably, 


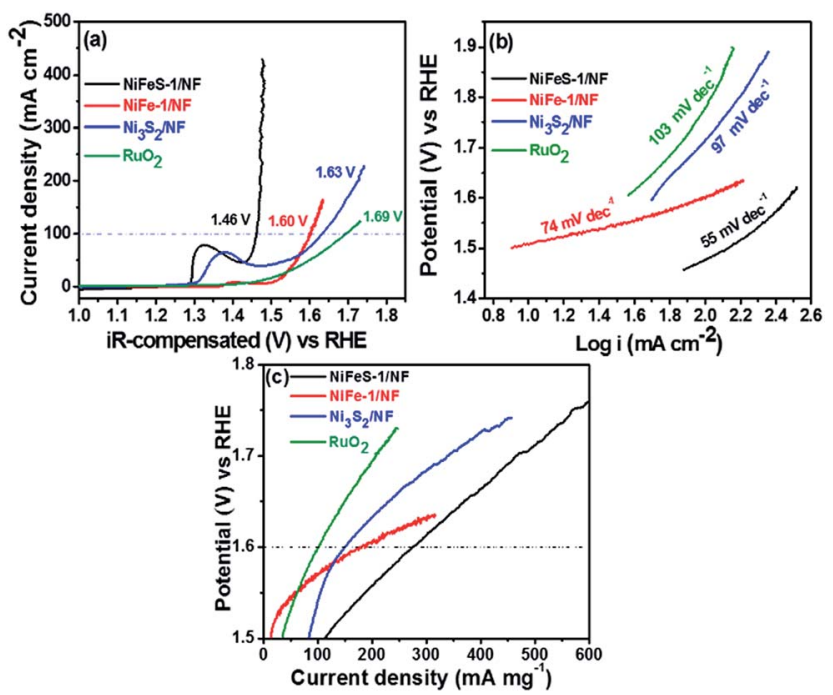

Fig. 5 (a) The OER polarisation curves and (b) the corresponding Tafel slopes of NiFeS-1/NF, NiFe-1/NF, $\mathrm{Ni}_{3} \mathrm{~S}_{2} / \mathrm{NF}$ and $\mathrm{RuO}_{2}$. (c) OER mass activity of $\mathrm{NiFeS}-1 / \mathrm{NF}, \mathrm{NiFe}-1 / \mathrm{NF}$ and $\mathrm{Ni}_{3} \mathrm{~S}_{2} / \mathrm{NF}$.

$\mathrm{RuO}_{2}$, one of the best precious metal bi-functional water oxidation catalysts, requires a large overpotential of $461 \mathrm{mV}$ to afford a current density of $100 \mathrm{~mA} \mathrm{~cm}^{-2}$ (Fig. 5a). The OER Tafel slopes for NiFeS-1/NF, NiFe-1/NF, and $\mathrm{Ni}_{3} \mathrm{~S}_{2} / \mathrm{NF}$ were 55,74 , and $97 \mathrm{mV} \mathrm{dec}^{-1}$, respectively (Fig. 5b); the Tafel slope for $\mathrm{RuO}_{2}$ was $103 \mathrm{mV} \mathrm{dec}^{-1}$ (Fig. 5b). Thus, the lowest Tafel slope was that for NiFeS-1/NF, indicative of facile electrode kinetics, possibly due to the formation of an active phase during the reversible oxidation of nickel iron sulphide to nickel iron oxy-sulphide. ${ }^{38}$ In general, the metal chalcogenides follow the reaction steps based on their corresponding metal oxide analogues. ${ }^{39}$

$$
\begin{gathered}
\mathrm{M}_{\mathrm{cat}} \mathrm{OH}^{-} \rightarrow \mathrm{M}_{\mathrm{cat}} \mathrm{OH}^{-}+\mathrm{e}^{-} \\
\mathrm{M}_{\mathrm{cat}} \mathrm{OH}^{-}+\mathrm{OH}^{-} \rightarrow \mathrm{M}_{\mathrm{cat}} \mathrm{O}^{\cdot}+\mathrm{H}_{2} \mathrm{O} \\
\mathrm{M}_{\mathrm{cat}} \mathrm{O}^{\cdot} \rightarrow \mathrm{SO}+\mathrm{e}^{-} \\
2 \mathrm{SO} \rightarrow 2 \mathrm{~S}+\mathrm{O}_{2}
\end{gathered}
$$

The adsorption of hydroxide on the catalyst surface plays an important role in the increased OER rate. The role of larger sulphur atoms in the NiFeS-1/NF facilitates more and easy adsorption of the $\mathrm{OH}^{-}$ions, which increases the rate of the reaction kinetics and favours a low Tafel slope value.

These results suggest that the combination of nickel, iron, and sulfur atoms in NiFeS-1/NF and NiFeS-2/NF provides higher current densities and lower overpotentials when compared with those of NiFe-1/NF, NiFe-2/NF, $\mathrm{Ni}_{3} \mathrm{~S}_{2} / \mathrm{NF}$, and NF electrodes. Further, the mass activities of the OER for NiFeS-1/NF, NiFe-1/ $\mathrm{NF}, \mathrm{Ni}_{3} \mathrm{~S}_{2} / \mathrm{NF}$ and $\mathrm{RuO}_{2}$ catalysts (Table 1 ) at $1.6 \mathrm{~V}$ are 276,178 , 149 and $100 \mathrm{~mA} \mathrm{mg}^{-1}$, respectively (Fig. 5c). The mass activity of the NiFeS-1/NF catalyst was $\sim 1.5$-fold higher than NiFe-1/NF, $\sim 1$.9-fold higher than $\mathrm{Ni}_{3} \mathrm{~S}_{2} / \mathrm{NF}$ catalysts and $\sim 2$.8-fold higher than $\mathrm{RuO}_{2}$, indicating the outstanding activity of the NiFeS-1/ NF catalyst. Also, the OER TOF of NiFeS-1/NF, NiFe-1/NF, $\mathrm{Ni}_{3} \mathrm{~S}_{2} /$ $\mathrm{NF}$ and $\mathrm{RuO}_{2}$ catalysts at $1.55 \mathrm{~V}$ is found to be $0.52,0.38,0.035$ and $0.046 \mathrm{~s}^{-1}$, respectively (Table 1 ). The TOF of the NiFeS-1/NF catalyst was $\sim 15$-fold higher than that of the $\mathrm{Ni}_{3} \mathrm{~S}_{2} / \mathrm{NF}$ catalyst and 11 -fold higher than that of a commercial noble metal OER catalyst, $\mathrm{RuO}_{2}$, indicating the incorporation of nickel, iron, and sulfur in the NiFeS-1/NF to improve the performance.

Based on the excellent OER activity of the NiFeS-1/NF catalyst, we also studied the HER activity in $1 \mathrm{M} \mathrm{KOH}$ electrolyte and compared it with several control catalysts. To achieve a current density of $-10 \mathrm{~mA} \mathrm{~cm}^{-2}$, the NiFeS-1/NF, NiFe-1/NF, and $\mathrm{Ni}_{3} \mathrm{~S}_{2} /$ NF catalysts required overpotentials of 180, 269, and $318 \mathrm{mV}$, respectively (Fig. 6a). We observed a similar trend among NiFeS2/NF, NiFe-2, and $\mathrm{Ni}_{3} \mathrm{~S}_{2} / \mathrm{NF}$ (Fig. S9b $\dagger$ ). The HER Tafel slopes of NiFeS-1/NF, NiFe-1/NF, and $\mathrm{Ni}_{3} \mathrm{~S}_{2} / \mathrm{NF}$ were 53,69 , and $74 \mathrm{mV}$ $\mathrm{dec}^{-1}$, respectively. Generally, transition metal chalcogenides follow the Tafel-Volmer-Heyrovsky mechanism (eqn (7)-(9)) in the alkaline medium. The rate determining step in the hydrogen evolution reaction for the low overpotential is Tafel and Volmer steps. Hence, compared to the control samples, the NiFeS-1/NF exhibits a low Tafel slope around $53 \mathrm{mV} \mathrm{dec}^{-1}$ due to the favourable Tafel and Volmer steps. ${ }^{\mathbf{4 0 , 4 1}}$

$$
\begin{gathered}
\mathrm{M}_{\mathrm{cat}}+\mathrm{H}_{2} \mathrm{O}+\mathrm{e}^{-} \rightleftharpoons \mathrm{M}_{\mathrm{cat}} \mathrm{H}_{\mathrm{ad}}+\mathrm{OH}^{-} \text {(Volmer reaction) } \\
\mathrm{M}_{\mathrm{cat}} \mathrm{H}_{\mathrm{ad}}+\mathrm{H}_{2} \mathrm{O}+\mathrm{e}^{-} \rightleftharpoons \mathrm{H}_{2}+\mathrm{M}_{\mathrm{cat}}+\mathrm{OH}^{-} \text {(Heyrovsky) } \\
2 \mathrm{M}_{\mathrm{cat}} \mathrm{H}_{\mathrm{ad}} \rightleftharpoons \mathrm{H}_{2}+\mathrm{M}_{\mathrm{cat}} \text { (Tafel) }
\end{gathered}
$$

In addition, compared with the HER activity of NiFeS-1/NF, the state-of-the-art Pt/C (40\%) catalyst exhibited an overpotential of $69 \mathrm{mV}$ at $-10 \mathrm{~mA} \mathrm{~cm}{ }^{-2}$ with a Tafel slope of $39 \mathrm{mV}$ $\operatorname{dec}^{-1}$ (Fig. 6b). This low HER performance of the NiFeS-1/NF

Table 1 OER and HER mass activities (MA) and turn over frequency (TOF) of various catalysts

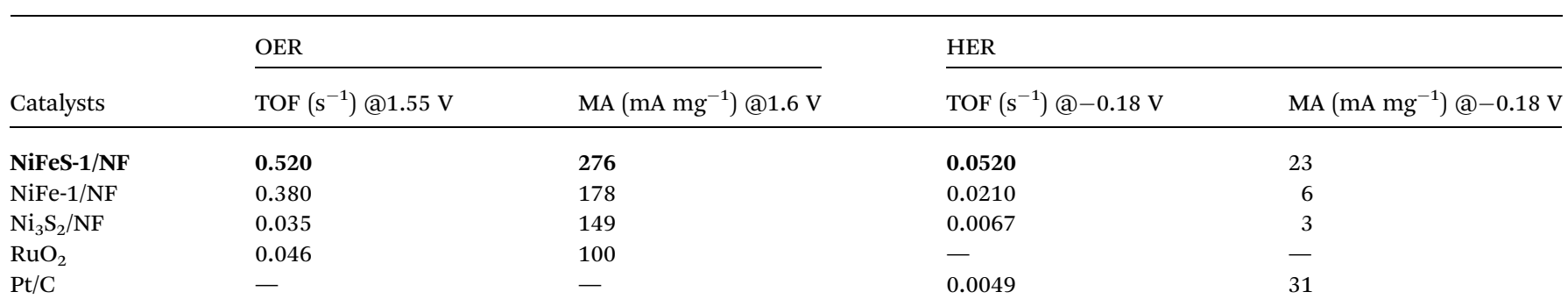




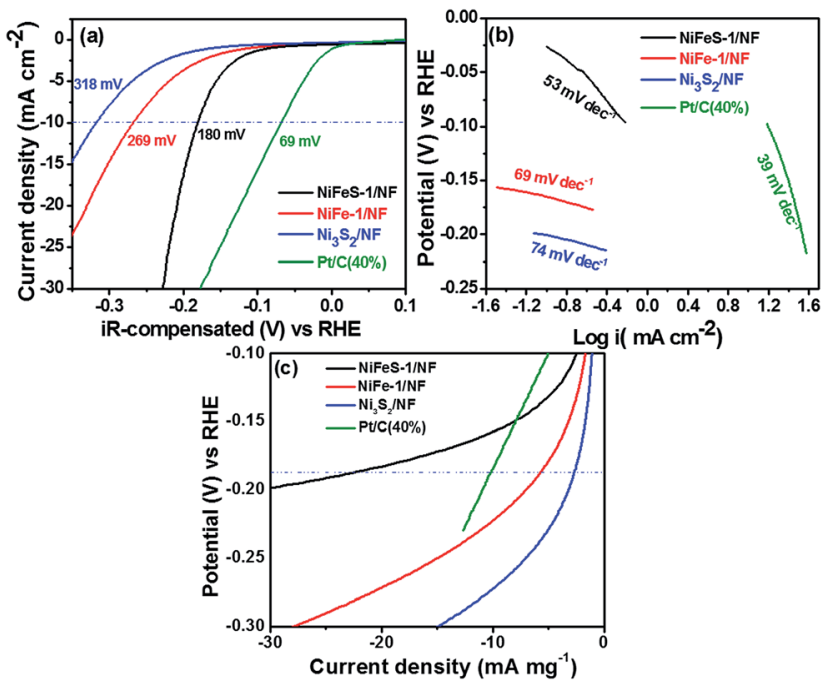

Fig. 6 (a) The HER polarisation curves and (b) the corresponding Tafel slopes of $\mathrm{NiFeS}-1 / \mathrm{NF}, \mathrm{NiFe}-1 / \mathrm{NF}, \mathrm{Ni}_{3} \mathrm{~S}_{2} / \mathrm{NF}$ and $\mathrm{RuO}_{2}$. (c) HER mass activity of $\mathrm{NiFeS}-1 / \mathrm{NF}, \mathrm{NiFe}-1 / \mathrm{NF}$ and $\mathrm{Ni}_{3} \mathrm{~S}_{2} / \mathrm{NF}$.

relative to $\mathrm{Pt} / \mathrm{C}(40 \%)$ may have been due to the decreased hydrogen adsorption and desorption of hydroxide species. Nevertheless, considering its low cost and facile coating, NiFeS1/NF displayed excellent HER activity. In addition, the HER mass activities of NiFeS-1/NF, NiFe-1/NF, $\mathrm{Ni}_{3} \mathrm{~S}_{2} / \mathrm{NF}$ and $\mathrm{Pt} / \mathrm{C}$ $(40 \%)$ catalysts at $-0.180 \mathrm{~V}$ are $23,6,3$ and $31 \mathrm{~mA} \mathrm{mg}{ }^{-1}$, respectively (Fig. 6c). The mass activity of the NiFeS-1/NF catalyst was $\sim 3$.8-fold higher than that of NiFe-1/NF and $\sim 7.5$-fold higher than that of the $\mathrm{Ni}_{3} \mathrm{~S}_{2} / \mathrm{NF}$ catalyst, but, slightly lower than $\mathrm{Pt} / \mathrm{C}(40 \%)$, indicating the outstanding HER activity of NiFeS-1/NF (Table 1). Moreover, the NiFeS-1/NF exhibits $\sim 8$ fold higher than Ni3S2/NF catalyst (Table 1). The OER performance of NiFeS-1/NF (231 mV@100 mA cm ${ }^{-2}$ ) is much better. The TOF of NiFeS-1/NF, NiFe-1/NF, $\mathrm{Ni}_{3} \mathrm{~S}_{2} / \mathrm{NF}$ and $\mathrm{Pt} / \mathrm{C}(40 \%)$ catalysts at $-0.180 \mathrm{~V}$ is $0.052,0.021,0.0067$ and $0.0049 \mathrm{~s}^{-1}$, respectively.
The TOF of the NiFeS-1/NF catalyst was $\sim 1$ order magnitude higher than that of a commercial HER Pt/C (40\%) catalyst and $\sim 8$-fold higher than that of $\mathrm{Ni}_{3} \mathrm{~S}_{2} / \mathrm{NF}$ catalysts (Table 1 ).

The OER performance of NiFeS-1/NF (231 mV@100 mA $\mathrm{cm}^{-2}$ ) is much better than those of the recently reported nonnoble catalysts such as $\mathrm{Fe}_{11.8 \%} \mathrm{Ni}_{3} \mathrm{~S}_{2} / \mathrm{NF}$ (253 mV@100 mA $\mathrm{cm}^{-2}$ ), ${ }^{15} \mathrm{NiFe}$ LDH/NF (269 mV@10 mA cm ${ }^{-2}$ ), ${ }^{42} \mathrm{NiFe}$ foam (320 mV@10 mA cm ${ }^{-2}$ ), ${ }^{10} \mathrm{Ni}_{3} \mathrm{Se}_{2}-\mathrm{Ni}$ foam (0.270 mV@10 mA $\left.\mathrm{cm}^{-2}\right),{ }^{43}$ oxidized carbon cloth (431 mV@10 mA cm $\left.{ }^{-2}\right),{ }^{44} \mathrm{CoM}$ nO@CN (334 mV@100 mA cm $\left.{ }^{-2}\right),{ }^{45} \mathrm{Co}(\mathrm{OH})_{2}$ (561 mV@100 mA $\left.\mathrm{cm}^{-2}\right){ }^{46}$ FeNi@NC (411 mV@100 mA cm $\left.{ }^{-2}\right)^{47}$ and DeLNiFeP/ rGO (271 mV@100 mA cm ${ }^{-2}$ ). ${ }^{23}$ Meanwhile, NiFeS-1/NF also outperforms the recently reported non-noble HER catalysts such as $\mathrm{Mo}_{2} \mathrm{C}$ (190@-10 mA cm $\left.{ }^{-2}\right)^{48}$ and $\mathrm{NiS}_{2} / \mathrm{GS}$ (190 mV@10 $\left.\mathrm{mA} \mathrm{cm}{ }^{-2}\right)^{21}$ (Table 2).

The superior activity of NiFeS-1/NF is also attributed to the fast electronic movement which can be understood from the Nyquist plot of NiFeS-1/NF and NiFe-1/NF as shown in Fig. 7a. The EIS data reveal a much smaller charge transfer resistance $\left(R_{\mathrm{ct}}\right)$ of about $20 \Omega$ for NiFeS-1/NF than that of NiFe-1/NF with $(43 \Omega)$. Moreover, the double layer capacitance $\left(C_{\mathrm{dl}}\right)$ extracted from the fitted Randles circuit as shown in Fig. 7a for NiFeS-1/ $\mathrm{NF}$ is $10 \mathrm{mF} \mathrm{cm}^{-2}$ (ref. 3 and 4 ) and for NiFe-1/NF is $3 \mathrm{mF} \mathrm{cm}^{-2}$. The higher capacitance of NiFeS-1/NF reflected its higher electrochemical active surface area (ECSA), presumably the main reason for its outstanding water splitting catalytic OER and HER performance (Table 1). ${ }^{\mathbf{1 9 , 4 5}}$

\section{Durability tests}

To examine the stability of the electrodes, we used the best NiFeS-1/NF catalyst to perform chronopotentiometry of the OER and HER for approximately $200 \mathrm{~h}$ each. Fig. $7 \mathrm{~b}$ presents the OER chronopotentiometry response of NiFeS-1/NF in $1 \mathrm{M} \mathrm{KOH}$ at a current density of $80 \mathrm{~mA} \mathrm{~cm}{ }^{-2}$ for $200 \mathrm{~h}$ of continuous operation. The NiFeS-1/NF electrode displayed an initial voltage of $1.6 \mathrm{~V}$; after $200 \mathrm{~h}$ of operation, it reached a voltage of $1.72 \mathrm{~V}$,

Table 2 Comparison of bi-functional OER and HER activities with recent non-precious catalysts in $1 \mathrm{M} \mathrm{KOH}^{a}$

\begin{tabular}{|c|c|c|c|c|c|}
\hline \multirow[b]{2}{*}{ Catalysts } & \multicolumn{2}{|l|}{ OER } & \multicolumn{2}{|l|}{ HER } & \multirow[b]{2}{*}{ References } \\
\hline & Overpotential $\eta(\mathrm{mV})$ & Durability test (h) & Overpotential $\eta(\mathrm{mV})$ & Durability test (h) & \\
\hline $\mathrm{NiFe}-1 / \mathrm{NF}$ & $371 @ 100 \mathrm{~mA} \mathrm{~cm}{ }^{-2}$ & NA & $318 @-10 \mathrm{~mA} \mathrm{~cm}^{-2}$ & NA & This work \\
\hline $\mathrm{Fe}_{11.8 \%} \mathrm{Ni}_{3} \mathrm{~S}_{2} / \mathrm{NF}$ & 253@100 mA cm ${ }^{-2}$ & 14 & NA & NA & 15 \\
\hline $\mathrm{NiFe}$ LDH/NF & 269@10 mA cm ${ }^{-2}$ & 0.5 & NA & NA & 38 \\
\hline $\begin{array}{l}\text { Oxidised carbon cloth } \\
\text { (ONPPGC/OCC) }\end{array}$ & 431@10 mA cm ${ }^{-2}$ & 10 & NA & NA & 40 \\
\hline CoMnO@CN & $334 @ 100 \mathrm{~mA} \mathrm{~cm}{ }^{-2}$ & 32 & NA & NA & 41 \\
\hline $\mathrm{Co}(\mathrm{OH})_{2}$ & $561 @ 100 \mathrm{~mA} \mathrm{~cm}-2$ & 2.9 & NA & NA & 42 \\
\hline FeNi@NC & 411@100 mA cm ${ }^{-2}$ & 2.5 & NA & NA & 43 \\
\hline DeLNiFeP/rGO & 271@100 mA cm ${ }^{-2}$ & 24 & NA & NA & 23 \\
\hline
\end{tabular}

${ }^{a} \mathrm{NA}$ - not available. 


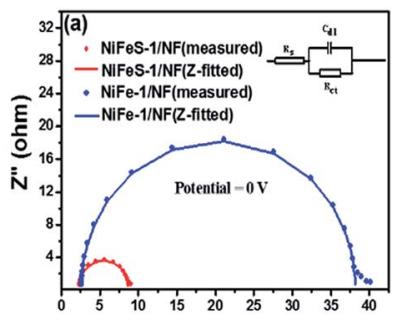

$Z^{\prime}$ (ohm)
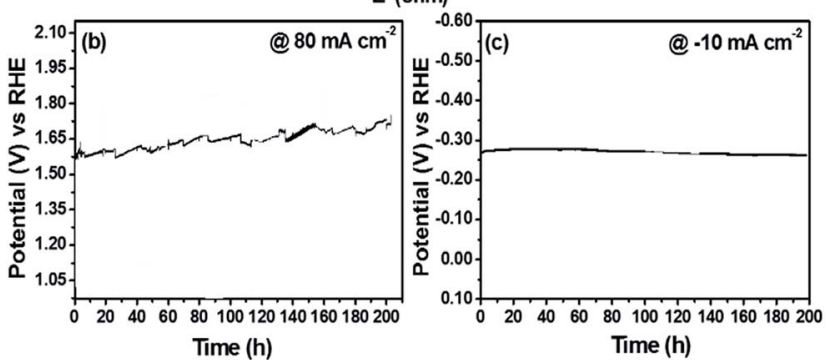

Fig. 7 (a) Electrochemical Z-fitted impedance spectra of NiFe-1/NF and NiFeS-1/NF (b) OER chronopotentiometric durability of NiFeS-1/ $\mathrm{NF}$ and (c) HER chronopotentiometric durability of NiFeS-1/NF.

corresponding to $7.5 \%$ decay. Moreover, the NiFeS-1/NF catalyst exhibited a HER performance loss of only $1.8 \%$ at the end of the $200 \mathrm{~h}$ HER stability test with a current density of $-10 \mathrm{~mA} \mathrm{~cm} \mathrm{~cm}^{-2}$ (Fig. 7c). These OER and HER chronopotentiometry stability results suggest that the NiFeS-1/NF catalyst exhibits excellent long-term stability in alkaline electrolytes. This outstanding stability of the NiFeS-1/NF electrode may be due to (i) the improved stability of nickel-incorporated iron in alkaline media, ${ }^{\mathbf{8 , 1 0 , 4 9}}$ (ii) the prevention of nickel corrosion by iron during prolonged operation in alkaline media, ${ }^{\mathbf{1 0}, 16}$ and (iii) the formation of an active phase during the electrochemical tuning of nickel iron sulphide to nickel iron oxy-sulphide, ${ }^{38}$ resulting in a highly durable HER and OER electrode for water splitting. Hence, alloying of iron with nickel and the incorporation of sulfur may have been responsible for the sustainable high current over the long period (200 h) of operation.

\section{Post analysis}

We examined the SEM morphology of the NiFeS-1/NF electrode after the $200 \mathrm{~h}$ OER and HER durability studies. Unlike the structure observed after the HER durability test, the SEM morphology observed for the electrode after the OER durability study featured wrecks at low magnification that is visible in Fig. S10a, $\dagger$ but its honeycomb structure remained undisturbed (Fig. S10c $\dagger$ ). We suspect that the wrecks found at low magnification were due to the prolonged bubble evolution during OER operation; these bubbles did not disturb the nanostructured honeycomb structure. After the HER durability test, no wrecks appeared in the low-magnification image (Fig. S10b $†$ ), and the honeycomb morphology was undisturbed at high magnification (Fig. S10d $\dagger$ ). Thus, the HER durability test did not disturb the morphology, in contrast to the electrode after the OER durability test.

We performed the post-XPS analysis of the NiFeS-1/NF electrode after the OER and HER tests to examine its surface properties. Compared with a fresh electrode, after the OER durability test the electrode had formed metal oxides that were responsible for its corrosion, whereas the HER durability test led to the formation of only a few metal sulfate impurities (Fig. S11 \& S12 $\dagger$ ). In addition, the OER electrode stability was tested using cyclic stability by CV measurements to understand the stability of NiFeS-1/NF. The cyclic stability measurement was examined by performing repeated potentiodynamic cycling for 5000 cycles in the potential range of 1.0 to $1.7 v s$. RHE at a scan rate of $50 \mathrm{mV} \mathrm{s}^{-1}$ (Fig. S13a $\dagger$ ). After 2500 and 5000 cycles, LSV for the NiFeS-1/NF catalyst was carried out which shows a loss of about 70 and $110 \mathrm{mV}$ at $100 \mathrm{~mA} \mathrm{~cm} \mathrm{~cm}^{-2}$, respectively (Fig. S13b $\dagger$ ). The gradual decrement in performance after 2500 and 5000 potentio-dynamic cycles was due to the oxidation of nickel and iron in the potential range of 1.3 to $1.45 \mathrm{~V}$. And after $5000 \mathrm{CV}$ cycles of cyclic measurements, the XRD pattern of the NiFeS-1/NF was analysed which exhibits the $\mathrm{Fe}_{11} \mathrm{Ni}_{8} \mathrm{~S}_{16}$ (PDF no. 00-022-067), $\mathrm{Fe}_{2} \mathrm{O}_{3}$ (PDF no. 00-039-0239) and $\mathrm{NiO}_{2}$ (PDF no. 01089-8397) phases (Fig. S13c $\dagger$ ). Hence, the XPS, and XRD studies reveal that the NiFeS-1/NF surface is partially oxidized to nickel oxide and iron oxide.

\section{MEA performance}

We examined the NiFeS-1/NF//AEM//NiFeS-1/NF and NF//AEM// $\mathrm{NF}$ electrodes individually as both anodes and cathodes for forming MEAs. Fig. 8a displays the water electrolyzer during electrochemical water splitting using NiFeS-1/NF as both the anode and cathode. Fig. $8 \mathrm{~b}$ presents the full water splitting properties in plots of the voltage versus current density operation of the electrolyzers constructed using NiFeS-1/NF (both

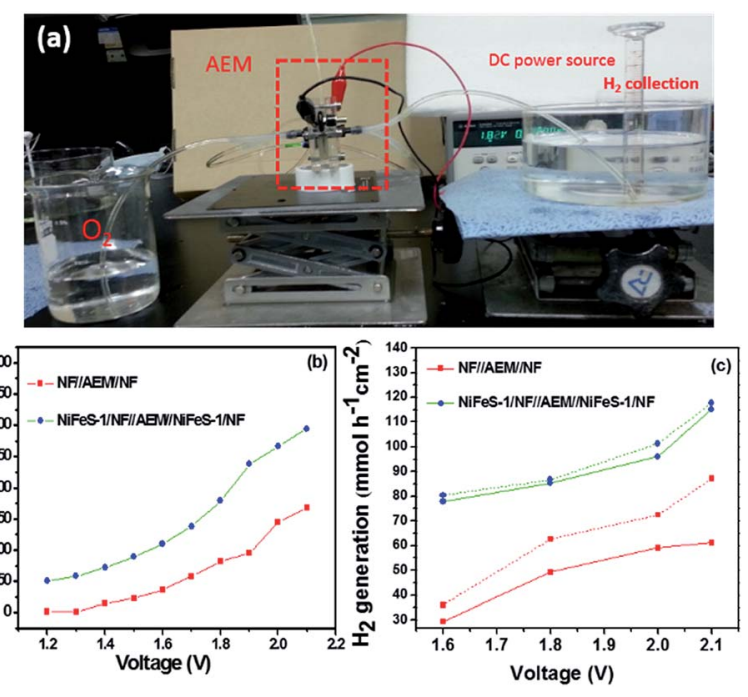

Fig. 8 (a) Alkaline electrolyte membrane (AEM) water electrolyzer set up during full water splitting. (b) Current density versus applied voltage plot of the PEM water electrolyzer using NiFeS-1/NF and NF as both the anode and cathode and (c) hydrogen generation rate in $\mathrm{mmol} \mathrm{h}^{-1}$ $\mathrm{cm}^{-2}$ for the PEM water electrolyzer using NiFeS-1/NF and NF alone as both the anode and cathode (solid line for $\mathrm{H}_{2}$ generation rate from displacement and dotted line for the $\mathrm{H}_{2}$ generation rate calculated from the coulombic charge). 
anode and cathode) for NiFeS-1/NF, and NF devices. The MEA constructed with NiFeS-1/NF exhibited $274 \mathrm{~mA} \mathrm{~cm}^{-2}$ at $2.0 \mathrm{~V}$. This performance is comparable with that of the recently reported channeled bipolar electrodes coated with $\mathrm{Pt} / \mathrm{C}$ as the catalyst. ${ }^{14}$ We calculated the amount of hydrogen produced from the displacement of water using these catalysts (Fig. 8c).

The amount of hydrogen generated during water electrolysis was $3.72 \mathrm{mmol} \mathrm{h}^{-1} \mathrm{~cm}^{-2}$ (Fig. 8c) which is close to the calculated coulombic efficiency from Fig. $8 \mathrm{~b}$ at $1.8 \mathrm{~V}$. Further, we analysed the morphology of the anode and cathode after the performance of the PEM assembly. The cathode exhibits the same honeycomb structure which shows that it was not severely affected (Fig. S14a and $\mathrm{b} \dagger$ ). But, in the case of the anode, the morphology was disturbed slightly (Fig. S14c and $\mathrm{d} \dagger$ ) due to the high anodic voltage operation. Also, the constructed alkaline water electrolyzer with $\mathrm{NiFeS-1/NF}$ exhibited performance similar to that of precious metal-based catalysts, suggesting the possibility of replacing them in alkaline electrolyte membrane water electrolyzers.

\section{Conclusions}

In summary, we have used a two-step, low-energy-consumption electrodeposition process for cost-effective deposition of nickel iron sulphide on NFs. From measurements of electrochemical activity, the NiFeS-1/NF catalyst exhibited a low OER overpotential of $231 \mathrm{mV}$, with this electrode generating a high current density of approximately $400 \mathrm{~mA} \mathrm{~cm}^{-2}$ at $1.47 \mathrm{~V}$; it also displayed an overpotential of $180 \mathrm{mV}$ for the HER, due to the composite effect of nickel, iron, and sulphide. This catalyst also displayed excellent durability, with continuous operation possible for approximately $200 \mathrm{~h}$ for the OER at $80 \mathrm{~mA} \mathrm{~cm} \mathrm{~cm}^{-2}$ and for the HER at $-10 \mathrm{~mA} \mathrm{~cm}^{-2}$. Furthermore, a PEM water electrolyzer constructed with NiFeS-1/NF electrodes displayed behaviour competitive with that of established systems.

\section{Acknowledgements}

The authors acknowledge the DGIST R\&D Program of the Ministry of Education, Science and Technology of Korea (16-RS-04) for financial support.

\section{Notes and references}

1 W. Zhu, X. Yue, W. Zhang, S. Yu, Y. Zhang, J. Wang and J. Wang, Chem. Commun., 2016, 52, 1486-1489.

2 M. S. Burke, L. J. Enman, A. S. Batchellor, S. Zou and S. W. Boettcher, Chem. Mater., 2015, 27, 7549-7558.

3 B. A. Pinaud, J. D. Benck, L. C. Seitz, A. J. Forman, Z. Chen, T. G. Deutsch, B. D. James, K. N. Baum, G. N. Baum, S. Ardo, H. Wang, E. Miller and T. F. Jaramillo, Energy Environ. Sci., 2013, 6, 1983-2002.

4 O. F. Selamet and M. S. Ergoktas, J. Power Sources, 2015, 281, 103-113.

5 C. D. Giovanni, A. Reyes-Carmona, A. Coursier, S. Nowak, J. M. Greneche, H. Lecoq, L. Mouton, J. Roziere, D. Jones,
J. Peron, M. Giraud and C. Tard, ACS Catal., 2016, 6, 26262631.

6 D. Pletcher and X. Li, Int. J. Hydrogen Energy, 2011, 36, 1508915104.

7 M. Carmo, D. L. Fritz, J. Mergel and D. Stolten, Int. J. Hydrogen Energy, 2013, 38, 4901-4934.

8 D. W. Kirk and S. J. Thorpe, ECS Trans., 2007, 14, 71-76.

9 W. Zhou, X. J. Wu, X. Cao, X. Huang, C. Tan, J. Tian, H. Liu, J. Wang and H. Zhang, Energy Environ. Sci., 2013, 6, 29212924.

10 Y. Liang, Q. Liu, A. M. Asiri, X. Sun and Y. He, Int. J. Hydrogen Energy, 2015, 40, 13258-13263.

11 N. Guijarro, M. S. Prevot, X. Yu, X. A. Jeanbourquin, P. Bornoz, W. Bouree, M. Johnson, F. L. Formal and K. Sivula, Adv. Energy Mater., 2016, 6, 1-13.

12 B. C. M. Martindale and E. Reisner, Adv. Energy Mater., 2016, 6, 1-9.

13 W. G. Colella, B. D. James, J. M. Moton, G. Saur and T. Ramsden, Techno-economic Analysis of PEM Electrolysis for Hydrogen Production, Electrolytic Hydrog. Prod. Work, http://energy.gov/sites/prod/, 2014.

14 G. Aragon-Gonzalez, A. Leon-Galicia, R. Gonzalez-Huerta, J. M. R. Camacho and M. Uribe-Salazar, J. Phys.: Conf. Ser., 2015, 582, 012054.

15 N. Cheng, Q. Liu, A. M. Asiri, W. Xing and X. Sun, J. Mater. Chem. A, 2015, 3, 23207-23212.

16 A. E. Mauer, D. W. Kirk and S. J. Thorpe, Electrochim. Acta, 2007, 52, 3505-3509.

17 L. L. Feng, G. Yu, Y. Wu, G. D. Li, H. Li, Y. Sun, T. Asefa, W. Chen and X. Zou, J. Am. Chem. Soc., 2015, 137, 1402314026.

18 R. Solmaz and G. Kardaş, Electrochim. Acta, 2009, 54, 37263734 .

19 X. Long, G. Li, Z. Wang, H. Zhu, T. Zhang, S. Xiao, W. Guo and S. Yang, J. Am. Chem. Soc., 2015, 137, 11900-11903.

20 S. Klaus, M. W. Louie, L. Trotochaud and A. T. Bell, J. Phys. Chem. C, 2015, 119, 18303-18316.

21 X. Wu, B. Yang, Z. Li, L. Lei and X. Zhang, RSC Adv., 2015, 5, 32976-32982.

22 T. Liu, A. M. Asiri and X. Sun, Nanoscale, 2016, 8, 3911-3915. 23 Y. Liu, H. Wang, D. Lin, C. Liu, P. C. Hsu, W. Liu, W. Chen and Y. Cui, Energy Environ. Sci., 2015, 8, 1719-1724.

24 N. Jiang, L. Bogoev, M. Popova, S. Gul, J. Yano and Y. Sun, J. Mater. Chem. A, 2014, 2, 19407-19414.

25 C. Tang, N. Cheng, Z. Pu, W. Xing and X. Sun, Angew. Chem., Int. Ed., 2015, 54, 9351-9355.

26 H. Zhu, J. Zhang, R. Yanzhang, M. Du, Q. Wang, G. Gao, J. Wu, G. Wu, M. Zhang, B. Liu, J. Yao and X. Zhang, Adv. Mater., 2015, 27, 4752-4759.

27 C. Xia, Q. Jiang, C. Zhao, M. N. Hedhili and H. N. Alshareef, Adv. Mater., 2016, 28, 77-85.

28 C. Tang, H. S. Wang, H. F. Wang, Q. Zhang, G. L. Tian, J. Q. Nie and F. Wei, Adv. Mater., 2015, 27, 4516-4522.

29 X. Lu and C. Zhao, Nat. Commun., 2015, 6, 6616.

30 S. W. Chou and J. Y. Lin, J. Electrochem. Soc., 2015, 162, A2762-A2769. 
31 J. Y. Lin, J. H. Liao and S. W. Chou, Electrochim. Acta, 2011, 56, 8818-8826.

32 J. S. Kang, M. A. Park, J. Y. Kim, S. H. Park, D. Y. Chung, S. H. Yu, J. Kim, J. Park, J. W. Choi, K. J. Lee, J. Jeong, M. J. Ko, K. S. Ahn and Y. E. Sung, Sci. Rep., 2015, 5, 10450. 33 X. Liu, X. Qi, Z. Zhang, L. Ren, Y. Liu, L. Meng, K. Huang and J. Zhong, Ceram. Int., 2014, 40, 8189-8193.

34 V. Biju and M. Abdul Khadar, J. Nanopart. Res., 2002, 4, 247253.

35 A. R. Lennie and D. J. Vaughan, Mineral Spectroscopy, 1996, 5, 117-131.

36 M. Descostes, F. Mercier, N. Thromat, C. Beaucaire and M. Gautier-Soyer, Appl. Surf. Sci., 2000, 165, 288-302.

37 T. Yamashita and P. Hayes, Appl. Surf. Sci., 2008, 254, 24412449.

38 W. Chen, H. Wang, Y. Li, Y. Liu, J. Sun, S. Lee, J. S. Lee and Y. Cui, ACS Cent. Sci., 2015, 1, 244-251.

39 M. E. G. Lyons and M. P. Brandon, Int. J. Electrochem. Sci., 2008, 3, 1425-1462.

40 I. Paseka, Electrochim. Acta, 1995, 40, 1633-1640.
41 A. Sivanantham, P. Ganesan and S. Shanmugam, Adv. Funct. Mater., 2016, 26, 4661-4672.

42 M. Gong, Y. Li, H. Wang, Y. Liang, J. Z. Wu, J. Zhou, J. Wang, T. Regier, F. Wei and H. Dai, J. Am. Chem. Soc., 2013, 135, 8452-8455.

43 A. T. Sedesi, J. Masud and M. Nath, Energy Environ. Sci., 2016, 9, 1771-1782.

44 J. Lai, S. Li, F. Wu, M. Saquib, R. Luque and G. Xu, Energy Environ. Sci., 2016, 9, 1210-1214.

45 J. Li, Y. Wang, T. Zhou, H. Zhang, X. Sun, J. Tang, L. Zhang, A. M. Al-Enizi, Z. Yang and G. Zheng, J. Am. Chem. Soc., 2015, 137, 14305-14312.

46 X. Zhou, X. Shen, Z. Xia, Z. Zhang, J. Li, Y. Ma and Y. Qu, ACS Appl. Mater. Interfaces, 2015, 7, 20322-20331.

47 X. Cui, P. Ren, D. Deng, J. Deng and X. Bao, Energy Environ. Sci., 2016, 9, 123-129.

48 C. G. Morales-Guio, L. A. Stern and X. Hu, Chem. Soc. Rev., 2014, 43, 6555-6569.

49 M. K. Bates, Q. Jia, H. Doan, W. Liang and S. Mukerjee, ACS Catal., 2016, 6, 155-161. 